\title{
Laparoscopic Anatomic Liver Resection of the Dorsal Part of Segment 8 Using an Hepatic Vein-Guided Approach
}

\author{
Kazuteru Monden, MD, FACS $\mathbb{C}^{\text {[ }}$, Hiroshi Sadamori, MD, PhD, Masayoshi Hioki, MD, PhD, \\ Satoshi Ohno, MD, PhD, and Norihisa Takakura, MD, PhD
}

Department of Surgery, Fukuyama City Hospital, Hiroshima, Japan

\begin{abstract}
Background. Laparoscopic anatomic liver resection is considered highly challenging, especially in segment 8 (S8), owing to the limited angle of the laparoscope and limited manipulation of the surgical instrument ${ }^{1,2}$. Additionally, resection is technically difficult when approaching the more peripheral branches since the Glissonean pedicle of S8 has several variations ${ }^{3}$ and is far from the hepatic hilum. The hepatic vein (HV)-guided approach involves entering from the cranial side of the liver while overcoming these difficulties with the unique view and techniques of laparoscopy ${ }^{4,5}$. We describe laparoscopic anatomic resection of the dorsal part of S8 using the HV-guided approach for hepatocellular carcinoma.

Methods . The drainage vein of segment 8 (V8), which often runs between the ventral and dorsal parts of $\mathrm{S} 8^{6,7}$, was exposed from the confluence of the middle HV to the periphery. The dorsal Glissonean branch of S8 (G8dor) was identified by deep dissection of the parenchyma on the right side of the V8. The right HV (RHV) was exposed toward the periphery after dissecting the G8dor. Liver parenchymal dissection was completed by connecting the demarcation line and the RHV.

Results. The total operation time was $319 \mathrm{~min}$, estimated blood loss was $5 \mathrm{~mL}$, and the patient was discharged on postoperative day 6 with no complications.
\end{abstract}

Supplementary Information The online version contains supplementary material available at https://doi.org/10.1245/s10434021-10488-y.

(C) Society of Surgical Oncology 2021

First Received: 6 April 2021

Accepted: 29 June 2021;

Published Online: 23 July 2021

K. Monden, MD, FACS

e-mail: monden0319@yahoo.co.jp
Conclusion. Laparoscopic anatomic resection of the dorsal parts of S8 could be safely performed by exposing the HVs from their roots and using the HVs as a landmark to identify the intrahepatic Glissonean pedicles.

DISCLOSURE Kazuteru Monden, Hiroshi Sadamori, Masayoshi Hioki, Satoshi Ohno, and Norihisa Takakura have no conflicts of interest to declare.

ETHICAL INFORMATION AND INFORMED CONSENT Written informed consent was obtained from all patients.

\section{REFERENCES}

1. Berardi G, Wakabayashi G, Igarashi K, et al. Full laparoscopic anatomical segment 8 resection for hepatocellular carcinoma using the glissonian approach with indocyanine green dye fluorescence. Ann Surg Oncol. 2019;26:2577-8.

2. Monden K, Alconchel F, Berardi G, et al. Landmarks and Techniques to perform minimally invasive liver surgery: A systematic Review with a Focus on hepatic outflow. J Hepatobiliary Pancreat Sci. 2021. https://doi.org/10.1002/jhbp.898.

3. Kobayashi T, Ebata T, Yokoyama Y, et al. Study on the segmentation of the right anterior sector of the liver. Surgery. 2017;161:1536-42.

4. Monden K, Sadamori H, Hioki M, Sugioka A. Laparoscopic anatomic segmentectomy 8 using the outer-Laennec approach. Surg Oncol. 2020;35:299-300.

5. Ome Y, Honda G, Doi M, Muto J, Seyama Y. Laparoscopic anatomic liver resection of segment 8 using intrahepatic glissonean approach. J Am Coll Surg. 2020;230:e13-20.

6. Taniai N, Machida T, Yoshida H, et al. Role of the anterior fissure vein in ventral or dorsal resection at Segment 8 of liver. Eur J Surg Oncol. 2018;44:664-9.

7. Cho A, Okazumi S, Makino H, et al. Relation between hepatic and portal veins in the right paramedian sector: proposal for anatomical reclassification of the liver. World J Surg. 2004;28:8-12.

Publisher's Note Springer Nature remains neutral with regard to jurisdictional claims in published maps and institutional affiliations. 